\begin{tabular}{lcl}
\hline Bentham open & The Open Materials Science Journal \\
CrossMark & Content list available at: www.benthamopen.com/TOMSJ/ \\
\hline
\end{tabular}

BOOK REVIEW

\title{
Book Review on Future Trends for TOP Materials
}

\author{
Norman S. Allen ${ }^{*}$ \\ Dalton Research Institute, Manchester Metropolitan University, Manchester, UK
}

The idea behind this book arose from a necessity typical from Organic Chemists. Exploration of search engines in diverse topics usually leads to isolated results on each certain thematic issue. Hence, a directed and simple approach seemed necessary. After a careful compilation, discussion of synthetic methodology, historical perspective and relevance is provided for each of the families of compounds here described. The most representative and notable examples are mentioned/scrutinized at historical level, either regarding synthetic aspects or applications (which can be across any field, from medical, biological or materials applications, among others).

This contribution focuses on defined compounds (or types of compounds) which are sure candidates to occupy a prominent place in synthesis (and in diverse applications) in the forthcoming years, for a large number of readers, who by any motivation want to explore new compounds for any given application. In this book, general and established synthetic methodologies for several compounds are also given, in an attempted way to provide straightforward approaches for researchers who intend to start new topics, as a hands on reference guide for scientists working in the fields of chemistry, physics, biology, biomedicine, materials science, polymer science, nanotechnology or supramolecular science.

This eBook is divided in 9 chapters, in following order: phthalocyanines, polymethines, porphyrins, BODIPYs, dendrimers, carbon allotropes, organic frameworks, nanoparticles and future prospects. Each chapter covers detailed synthetic aspects of the most established preparation routes for each type of compounds, while giving a historical perspective, with selected information on actual and outstanding applications of each material, unraveling what likely might be the future for each one. I would like to refer to the last chapter, which deals with the synthesis and functionalization of several types of inorganic nanoparticles, but emphasizing the organic functionalization of such inorganic materials.

Bottom-line, it is intended to provide a clear concept on each section as a "since when/how/why/what's next" overall idea, targeted for researchers either from industries or universities, who by any motivation want to explore new compounds for any given application, providing general and established synthetic approaches, or to readers who would like to know more in a concise manner, without spending unnecessary efforts on isolated thematic search through available search engines.

\section{(C) Norman S. Allen; Licensee Bentham Open}

This is an open access article licensed under the terms of the Creative Commons Attribution-Non-Commercial 4.0 International Public License (CC BY-NC 4.0) (https://creativecommons.org/licenses/by-nc/4.0/legalcode), which permits unrestricted, non-commercial use, distribution and reproduction in any medium, provided the work is properly cited.

\footnotetext{
* Address correspondence to this author at the Dalton Research Institute, Manchester Metropolitan University, Manchester, UK; Email: norman_allen@sky.com
} 